\title{
Inhibitory effect of secretin and cholecystokinin on Heidenhain pouch responses to gastrin extract and histamine
}

\author{
IAIN E. GILLESPIE AND MORTON I. GROSSMAN \\ From the Gastroenterology Section, Veterans Administration Center, \\ Los Angeles 25, California, U.S.A.
}

EDITORIAL SYNOPSIS Rapid intravenous injections of secretin and cholecystokinin (Vitrum) inhibited the acid response of Heidenhain pouch dogs to continuous intravenous gastrin extract. Cholecystokinin caused greater inhibition than secretin. Responses to small doses of histamine were inhibited by cholecystokinin but not by secretin.

Since Sokolov in 1904 first showed that acid coming in contact with duodenal mucosa inhibited gastric acid secretion, opinion has been divided regarding the mechanism of this inhibition. Although earlier work by Code and Watkinson (1955) had suggested that intact vagal innervation was essential for this form of inhibition, more recent studies by Andersson (1960a, b, c, d, e) have demonstrated marked inhibitory effects where no attempt was made to preserve vagal fibres. The results of these and other studies strongly suggest that a humoral inhibitory substance is released from duodenal mucosa on acidification. It thus seemed reasonable to investigate further the possibility that extracts of duodenal mucosa might display inhibitory properties. Before embarking on the preparation of extracts from fresh material it was decided in the first instance to test those duodenal mucosal extracts already commercially available, namely secretin and cholecystokinin. The results of the present study indicate that when given by rapid intravenous injection the secretin extract can inhibit the response of a Heidenhain pouch to injected gastrin extract and the cholecystokinin extract can inhibit the response of such a pouch both to gastrin extract and to histamine.

\section{MATERIALS AND METHODS}

Five dogs with Heidenhain type denervated fundic pouches created more than six months previously were studied.

Secretin and cholecystokinin, prepared by the method of Jorpes and Mutt (1959), were obtained from Vitrum (Stockholm). Gastrin extract was prepared from hog antral mucosa by a modification of the method of Gregory and Tracy (1961) previously described (Gillespie and Grossman, 1963); doses are expressed as the equivalent weight in grams of wet antral mucosa.

The dogs were deprived of food overnight before each test. The inhibitory action of the secretin and cholecystokinin was tested against a background of secretion stimulated by continuous intravenous infusion of gastrin extract or histamine given throughout each experiment by a Sigmamotor pump, the rate of flow being $20 \mathrm{ml}$. per hour. The concentration of gastrin extract or of histamine dihydrochloride in $0.9 \%$ sodium chloride solution was adjusted to give the desired dose rates. After the response had reached a plateau of at least four approximately equal successive 15 -minute collections, a single intravenous injection of secretin or cholecystokinin (75 clinical units $=0 \cdot 1 \mathrm{mg}$. for secretin, $3 \mathrm{mg}$. for cholecystokinin) was given and collections were continued at 15-minute intervals for at least one and a half hours.

The acid concentration was determined by titration with $0 \cdot 2 \mathrm{~N}$ sodium hydroxide with phenol red indicator. The results are given as microequivalents per 15 minutes. The control output is the mean of the four 15-minute outputs immediately preceding the secretin or cholecystokinin injection, each subsequent 15-minute output being expressed as a percentage of the control response. In all instances duplicate observations were made on each dog.

\section{RESULTS}

Table I shows the effect of secretin on the response to gastrin extract, which was given throughout at a rate of $2.5 \mathrm{~g}$. per hour. Inhibition occurred rapidly after the secretin injection, being present within 15 minutes and statistically significant for 30 minutes, after which there was a return of control levels. 


\section{TABLE I}

EFFECT OF SINGLE INTRAVENOUS INJECTION OF SECRETIN (75 CLINICAL UNITS) ON ACID RESPONSE OF HEIDENHAIN POUCH TO CONTINUOUS INTRAVENOUS INJECTION OF GASTRIN EXTRACT, $2 \cdot 5 \mathrm{~g}$. PER HOUR

Dog No. Control ${ }^{1} \quad$ Post-injection 15-min. Acid Outputs $(\mu E q . / 15$ min.)

Expressed as \% of Control

\begin{tabular}{lrrrrrrr} 
& & 1 & 2 & 3 & 4 & 5 & 6 \\
\hline 43 & 106 & 71 & 14 & 61 & 125 & 43 & 67 \\
43 & 85 & 62 & 21 & 36 & 92 & 74 & 87 \\
44 & 102 & 65 & 120 & 192 & 120 & 98 & 64 \\
44 & 151 & 56 & 54 & 47 & 36 & 23 & 23 \\
45 & 36 & 53 & 0 & 175 & 153 & 139 & 328 \\
45 & 18 & 50 & 44 & 167 & 200 & 217 & 150 \\
48 & 281 & 59 & 70 & 79 & 61 & 73 & 106 \\
48 & 186 & 40 & 75 & 86 & 65 & 51 & 67 \\
53 & 197 & 55 & 13 & 45 & 92 & 74 & 53 \\
53 & 213 & 25 & 9 & 42 & 89 & 110 & 109 \\
Means & 138 & $54 * *$ & $42 * *$ & 93 & 103 & 90 & 105
\end{tabular}

${ }^{1}$ Control is mean of four 15 -minute outputs immediately preceding injection.

Asterisks indicate statistically significant difference from control ** $\mathrm{P}<0.01$.

Table II shows that inhibition of the response to gastrin extract also followed a single cholecystokinin injection. The inhibition, though statistically significant for 75 minutes after the injection, appeared to develop more slowly, being maximal in the third 15-minute period. The degree of inhibition was also greater, the mean maximal being $78 \%$ as compared with $58 \%$ in the case of secretin (Table I).

In studying the effect of secretin and cholecystokinin on the responses to histamine two separate dose rates of histamine dihydrochloride were used.

In the first instance the acid response to the continuous intravenous injection of histamine dihydrochloride, $0.25 \mathrm{mg}$. per hour, was found to be unaffected by either secretin (Table IIIA) or cholecystokinin (Table IV).

However, it was noted that the mean control acid outputs to this dose of histamine, 280 and $331 \mu \mathrm{Eq}$. per 15 minutes respectively, were approximately twice the mean control acid outputs to $2.5 \mathrm{~g}$. gastrin extract per hour (138 and $166 \mu \mathrm{Eq}$. per 16 minutes). It seemed desirable to test for inhibition against comparable acid responses to the two secretory stimulants. For this reason, and also on account of the possibility that histamine might be more resistant to inhibitory influences than gastrin, the experiments were repeated in the same dogs using $\mathbf{0} \cdot 125 \mathrm{mg}$. histamine dihydrochloride per hour, half the previous dose rate. Table IIIB shows that secretin was still without effect on the acid response to this dose of histamine. Table IVB, however, shows that cholecystokinin did cause statistically significant inhibition, of the same intensity and duration as the depression of the gastrin extract response by cholecystokinin.
TABLE II

EFFECT OF SINGLE INTRAVENOUS INJECTION OF CHOLECYSTOKININ (75 CLINICAL UNITS) ON ACID RESPONSE OF HEIDENHAIN POUCH TO CONTINUOUS

INTRAVENOUS INJECTION OF GASTRIN EXTRACT, $2.5 \mathrm{~g}$. PER HOUR

Dog No. Control ${ }^{1} \quad$ Post-injection 15-min. Acid Outputs ( $\mu$ Eq./15 min.) Expressed as \% of Control

\begin{tabular}{llllll}
\hline 1 & 2 & 3 & 4 & 5 & 6
\end{tabular}

\begin{tabular}{lrrrrrrrr}
\hline 43 & 30 & 60 & 17 & 27 & 10 & 93 & 280 \\
43 & 71 & 37 & 10 & 4 & 42 & 24 & 23 \\
44 & 230 & 72 & 27 & 40 & 91 & 104 & 85 \\
44 & 62 & 61 & 13 & 18 & 24 & 100 & 116 \\
45 & 152 & 84 & 23 & 11 & 63 & 94 & 86 \\
45 & 162 & 82 & 28 & 4 & 9 & 37 & 33 \\
48 & 417 & 49 & 11 & 10 & 34 & 57 & 51 \\
48 & 121 & 36 & 12 & 11 & 11 & 67 & 31 \\
53 & 174 & 97 & 71 & 9 & 5 & 39 & 100 \\
53 & 242 & 102 & 93 & 86 & 112 & 130 & 100 \\
Means & 166 & $68 * *$ & $30^{* *}$ & $22^{* *}$ & $\mathbf{4 0 * *}$ & $76^{* *}$ & 90
\end{tabular}

${ }^{1}$ Control is mean for four 15 -minute outputs immediately preceding injection.

Asterisks indicate statistically significant difference from control ** $P<0.01$

\section{TABLE III}

EFFECT OF SINGLE INTRAVENOUS INJECTION OF SECRETIN (75 CLINICAL UNITS) ON ACID RESPONSE OF HEIDENHAIN POUCH TO CONTINUOUS INTRAVENOUS INJECTION OF HISTAMINE DIHYDROCHLORIDE

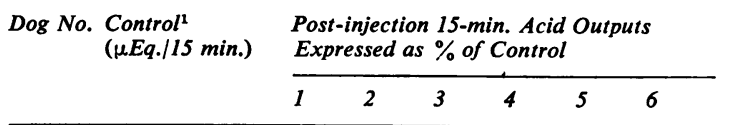

\begin{tabular}{lcrrrrrr}
\hline A & Histamine dihydrochloride, $0 \cdot 25$ mg. per hour \\
43 & 70 & 110 & 113 & 154 & 133 & 113 & 167 \\
43 & 189 & 83 & 123 & 87 & 87 & 80 & 95 \\
44 & 163 & 66 & 102 & 104 & 102 & 101 & 111 \\
44 & 217 & 67 & 90 & 93 & 103 & 97 & 90 \\
45 & 219 & 79 & 58 & 75 & 101 & 60 & 90 \\
45 & 268 & 83 & 121 & 188 & 187 & 132 & 152 \\
48 & 456 & 109 & 128 & 113 & 108 & 104 & 103 \\
48 & 443 & 100 & 91 & 84 & 94 & 97 & 98 \\
53 & 498 & 66 & 73 & 84 & 77 & 65 & 71 \\
53 & 272 & 72 & 110 & 101 & 88 & 89 & 103 \\
Means & 280 & 83 & 101 & 108 & 108 & 94 & 108
\end{tabular}

B Histamine dihydrochloride, $0 \cdot 125 \mathrm{mg}$. per hour

$\begin{array}{lrrrrrrr}43 & 60 & 67 & 127 & 112 & 85 & 45 & 135 \\ 43 & 103 & 82 & 103 & 98 & 55 & 110 & 75 \\ 44 & 70 & 103 & 180 & 136 & 115 & 123 & 129 \\ 44 & 38 & 142 & 187 & 179 & 153 & 116 & 111 \\ 45 & 31 & 184 & 123 & 55 & 461 & 213 & 216 \\ 45 & 189 & 61 & 93 & 93 & 110 & 123 & 122 \\ 48 & 280 & 117 & 94 & 63 & 58 & 64 & 99 \\ 48 & 280 & 93 & 118 & 120 & 114 & 85 & 98 \\ 53 & 126 & 94 & 111 & 119 & 138 & 79 & 107 \\ 53 & 173 & 80 & 53 & 100 & 70 & 70 & 51 \\ \text { Means } & 135 & 104 & 119 & 108 & 131 & 103 & 114\end{array}$

${ }^{1}$ Control is mean of four 15 -minute outputs immediately preceding injection.

In no instance is the difference between post-injection output and control statistically significant. 


\section{TABLE IV}

EFFECT OF SINGLE INTRAVENOUS INJECTION OF CHOLECYSTOKININ (75 CLINICAL UNITS) ON ACID RESPONSE OF HEIDENHAIN POUCH TO CONTINUOUS INTRAVENOUS INJECTION OF HISTAMINE DIHYDROCHLORIDE

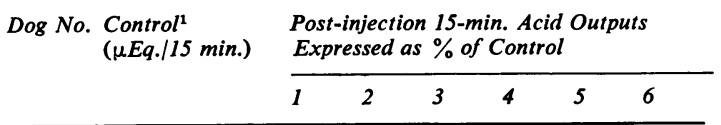

\begin{tabular}{lcrrrrrr}
\hline A & Histamine dihydrochloride, $0 \cdot 25$ & mg. & per hour & & \\
43 & 190 & 75 & 39 & 95 & 58 & 47 & 47 \\
43 & 227 & 51 & 96 & 78 & 36 & 66 & 51 \\
44 & 170 & 66 & 54 & 74 & 58 & 47 & 69 \\
44 & 198 & 57 & 13 & 12 & 28 & 28 & 38 \\
45 & 447 & 81 & 42 & 42 & 62 & 69 & 76 \\
45 & 314 & 83 & 54 & 53 & 32 & 76 & 85 \\
48 & 663 & 60 & 4 & 8 & 23 & 24 & 21 \\
48 & 436 & 31 & 2 & 6 & 11 & 20 & 39 \\
53 & 315 & 214 & 273 & 310 & 291 & 224 & 248 \\
53 & 353 & 138 & 138 & 155 & 160 & 165 & 156 \\
Means & 331 & 86 & 71 & 81 & 76 & 77 & 83 \\
$B$ & Histamine dihydrochloride, $0 \cdot 125$ & mg. & per & hour & & & \\
43 & 78 & 46 & 72 & 47 & 46 & 35 & 64 \\
43 & 87 & 54 & 9 & 3 & 13 & 29 & 37 \\
44 & 88 & 51 & 8 & 8 & 7 & 9 & 16 \\
44 & 41 & 37 & 0 & 0 & 20 & 44 & 78 \\
45 & 80 & 66 & 23 & 21 & 13 & 28 & 41 \\
45 & 212 & 52 & 7 & 2 & 3 & 12 & 39 \\
48 & 199 & 89 & 10 & 2 & 3 & 3 & 3 \\
48 & 266 & 27 & 3 & 0 & 0 & 2 & 6 \\
53 & 138 & 183 & 54 & 15 & 37 & 51 & 67 \\
53 & 193 & 122 & 58 & 56 & 78 & 88 & 93 \\
Means & 138 & 73 & $24 * *$ & $15 * *$ & $22 * *$ & $30^{* *}$ & $44 * *$ \\
\hline & & & & & & &
\end{tabular}

${ }^{1}$ Control is mean of four 15 -minute outputs immediately preceding injection.

Asterisks indicate statistically significant difference from control $* \mathbf{P}<0.01$.

\section{DISCUSSION}

Greenlee, Londhi, Guerrero, Nelsen, El-Bedri, and Dragstedt (1957) reported that in dogs intravenous injections of secretin (Lilly) inhibited the response to feeding and to antral pouch stimulation, but not to vagal stimulation or histamine. It was further shown by Kennedy and Hallenbeck (1963) that the inhibitory effect of intravenous secretin was unaffected by removal of the pancreas. Thomford, Kennedy, and Hallenbeck (1963) found that intravenous secretin (Vitrum) failed to reduce the response of a Heidenhain pouch to intragastric ethyl alcohol. As a result of these studies it was concluded that the mechanism by which the inhibition was mediated was suppression of gastrin release. The present studies would seem to indicate interference with the action of circulating gastrin by the secretin and cholecystokinin preparations used.

It is apparent from the experiments with both gastrin extract and histamine that cholecystokinin possesses greater inhibitory properties than secretin. Neither the secretin nor cholecystokinin preparations are pure substances, and the fact that the dose of cholecystokinin contained a larger quantity of protein material ( $3 \mathrm{mg}$. as compared with $0 \cdot 1 \mathrm{mg}$. in the case of secretin) suggests that the cholecystokinin extract contained a greater amount of contaminating factors. It is thus possible that a single agent common to both preparations and additional to the pure hormones themselves is responsible for the inhibition.

However, it is known that the cholecystokinin extract exhibits slight secretin activity, and the possibility arises that secretin itself may have inhibitor properties. This view was favoured by Jordan and Peterson (1962), who found similar degrees of inhibition of the response to a meal after the intravenous injection of two separate secretin preparations of widely differing purity. It will be of great interest to ascertain whether a much purer preparation of secretin which has recently become available (Jorpes, Mutt, Magnusson, and Steele, 1962) inhibits the response of the fundic glands to gastrin extract.

The finding that the inhibitory property of cholecystokinin lessened when the stimulating dose of histamine was increased may indicate that the inhibition was relatively weak. On the other hand the increased dose of histamine would have evoked a greater acid response not only from the Heidenhain pouch but also simultaneously from the main stomach remnant. Thus a greater amount of acid would have entered the duodenum during the administration of the larger dose of histamine. It is possible, therefore, that the larger gastric acid responses resulted in the liberation of maximal amounts of endogenous humoral inhibitory agent and that consequently the injection of further inhibitor substance as secretin or cholecystokinin extracts was without additional effect. This hypothesis represents the behaviour pattern which might be expected if secretin were the inhibitory agent, since acid in the duodenum is a well-known potent stimulus for release of secretin.

The differences between the inhibition of the responses to gastrin extract and to histamine suggest that histamine is more resistant to inhibitory influences than gastrin. Comparison has already been made between approximately matched control responses to both gastrin extract and histamine, i.e., to $2.5 \mathrm{~g}$. gastrin extract per hour and $0.125 \mathrm{mg}$. histamine dihydrochloride per hour. It was seen that secretin inhibited only the response to gastrin extract. It has been previously reported (Gillespie and Grossman, 1963) that in Heidenhain pouch dogs the maximal gastrin response is less than the maximal histamine response. In the present group of dogs separate studies showed that the mean maximal gastrin response was $44 \%$ of the mean maximal histamine response. If comparison is made between controls, not as equivalent absolute responses but as comparable proportions of a 
maximal attainable by the appropriate stimulant, it might be more relevant to compare the gastrin extract experiments with those in which $0.25 \mathrm{mg}$. histamine dichloride was given. This approach further emphasizes the lesser susceptibility of histamine to the inhibitory agents.

Andersson found that in dogs acidification of the duodenum inhibited the response of the fundic glands to injected gastrin extract (Andersson, 1960d) but only slightly and inconstantly to histamine (Andersson, 1960e). It is possible that this difference may be accounted for by the relative resistance of histamine to inhibitory influences, and it would be of interest to repeat Andersson's experiments using smaller stimulatory doses of histamine. The overall similarities in the present studies of inhibition by extracts and in those of duodenal acidification raise the possibility that the humoral substance released by duodenal acidification is contained in secretin and cholecystokinin extracts.

The technical assistance of John L. Washington is gratefully acknowledged.

This work was supported in part by grants from the United States Public Health Service (AM-03326) and from the National Science Foundation (G-8800), and performed during the tenure of a United States Public Health Services post-doctoral research fellowship by I. E. Gillespie.

\section{REFERENCES}

Andersson, S. (1960a). Inhibitory effects of acid in antrum-duodenum on fasting gastric secretion in Pavlov and Heidenhain pouch dogs. Acta physiol. scand., 49, 42-56.
- (1960b). Inhibitory effects of hydrochloric acid in antrum and duodenum on gastric secretory responses to test meal in Pavlov and Heidenhain pouch dogs. Ibid., 49, 231-241.

- (1960c). Inhibitory effects of hydrochloric acid in antrum and duodenum on gastric secretory responses to insulin hypoglycemia in Pavlov pouch dogs. Ibid., 50, 23-31.

- (1960d). Inhibitory effects of hydrochloric acid in the duodenum on gastrin-stimulated gastric secretion in Pavlov and Heidenhain pouch dogs. Ibid., 50, 105-112.

- (1960e). Inhibitory effects of hydrochloric acid in antrum and duodenum on histamine-stimulated gastric secretion in Pavlov and Heidenhain pouch dogs. Ibid., 50, 186-196.

Code, C. F., and Watkinson, G. (1955). Importance of vagal innervation in the regulatory effect of acid in the duodenum on gastric secretion of acid. J. Physiol. (Lond.), 130, 233-252.

Gillespie, I. E., and Grossman, M. I. (1963). Inhibition of gastric secretion by extracts containing gastrin. Gastroenterology, 44, 301-310.

Greenlee, H. B., Londhi, E. H., Guerrero, J. D., Nelsen, T. S., El-Bedri, A. L., and Dragstedt, L. R. (1957). Inhibitory effect of pancreatic secretion on gastric secretion. Amer. J. Physiol., $190,396-402$.

Gregory, R. A., and Tracy, H. J. (1961). The preparation and properties of gastrin. J. Physiol. (Lond.), 156, 523-543.

Jordan, P. H. Jr., and Peterson, N. D. (1962). Effects of secretin upon gastric secretion. Ann. Surg., 156, 914-923.

Jorpes, J. E., and Mutt, V. (1959). Secretin, pancreozymin, and cholecystokinin. Their preparation and properties. Gastroenterology, 36, 377-385.

- - - Magnusson, S., and Steele, B. B. (1962). Amino acid composition and $\mathrm{N}$-terminal amino acid sequence of porcine secretin. Biochem. biophys. Res. Commun., 9, 275-279.

Kennedy, J. A., and Hallenbeck, G. A. (1963). The pancreas and gastric secretion: failure of pancreatectomy to prevent inhibition of gastric secretion by secretin. Gut, 4, 58-60.

Sokolov, A. P. (1904). Analysis of the secretory work of the stomach in the dog. Thesis, Vaisberg $\mathrm{K}$ Gershunim, St. Petersburg, 1904. Quoted by B. P. Babkin, in Secretory Mechanisms of the Digestive Glands, 2nd ed., pp. 463-495, Hoeber, New York, 1950.

Thomford, N. R., Kennedy, J. A., and Hallenbeck, G. A. (1963). Failure of secretin or duodenal acidification to inhibit ethanolinduced $\mathrm{HCl}$ secretion by Heidenhain pouches. Proc. Soc. exp. Biol. (N.Y.), 112, 1000-1002. 